\title{
Evaluation of the relationship of IL-17A and IL-17F gene polymorphisms with the response to treatment in psoriatic patients using biological drugs: a case-control study in patients in Eastern Turkey
}

\author{
${ }^{1}$ Department of Dermatology, Faculty of Medicine, Yuzuncu Yil University, Van, Turkey \\ ${ }^{2}$ Department of Medical Biology, Faculty of Medicine, Yuzuncu Yil University, Van, Turkey \\ ${ }^{3}$ Department of Biostatistics, Faculty of Medicine, Yuzuncu Yil University, Van, Turkey \\ ${ }^{4}$ Department of Dermatology, Erzincan State Hospital, Erzincan, Turkey
}

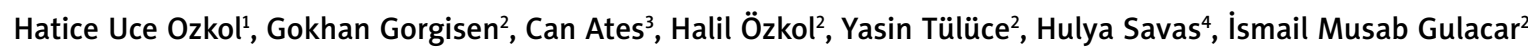

Adv Dermatol Allergol 2021; XXXVIII (5): 780-787 DOI: https://doi.org/10.5114/ada.2020.95383

\begin{abstract}
Introduction: IL-17A and IL-17F cytokines have important roles in the pathogenesis of psoriasis.

Aim: To examine the associations of IL-17A rs2275913 and IL-17F rs763780 variants with the development of psoriasis and whether these polymorphisms affect the responsiveness of biological agents.

Material and methods: In our case-controlled study, which included 83 psoriatic patients who were treated with different biological agents and 69 healthy controls, we genotyped IL-17A rs2275913 and IL-17F rs763780 variants using TaqMan probes.

Results: We did not observe statistically significant changes in genotype frequencies of IL-17A rs2275913 $(p=0.922)$ and IL-17F rs763780 ( $p=0.621$ ) variants between patient and control groups. Although we did not find any association between these polymorphisms and the development of psoriasis, statistical analyses showed that individuals with the IL-17A AA genotype had shorter disease duration $(9.09 \pm 6.82, p=0.020)$ and AA genotype frequency was higher in patients who used single conventional treatment $(34.6 \% ; p=0.025)$. IL17A/rs2275913 variant in terms of disease duration, it was observed that individuals with AA genotype had a shorter disease duration (less than 10 years) ( $p=0.009$ ). For patients with PASI90 and PASI100 response, the IL-17A AA genotype was significantly higher $(p=0.015)$. On the other hand, we did not detect any statistically significant correlation between variants and response to biological agents.

Conclusions: According to our results, we may suggest that rs2275913 variant seems to be associated with disease duration, use of single conventional treatment and responsiveness of PASI90 and PASI100 however both variants have no effect on the susceptibility to psoriasis in the population of Eastern Turkey.
\end{abstract}

Key words: psoriasis, IL-17A, IL-17F, secukinumab, adalimumab, ustekinumab.

\section{Introduction}

Psoriasis is a frequently encountered chronic inflammatory skin disease that is an important global health problem today. Population studies, twin studies, family tree reviews and human leukocyte antigens (HLA) associations support that psoriasis is an inherited disease. The percentage of hereditary transition among the patients is unknown, and the heredity type could not be determined clearly [1, 2]. It has been suggested that he- reditary sensory alleles and environmental risk factors play a significant role in the pathogenesis of psoriasis [3]. Genome-wide association studies (GWAS) demonstrated that psoriasis has a multifactorial genetics and that there is a correlation between some haplotypes of HLA. In particular, a strong relationship has been shown between HLA-CW6 and early-onset psoriasis [4].

Numerous cytokines have been implicated in the pathogenesis of psoriasis, such as tumor necrosis fac-

Address for correspondence: Hatice Uce Ozkol MD, Department of Dermatology, Faculty of Medicine, Yuzuncu Yil University, 65100 Van, Turkey, phone: +90 43221576 07, fax: +90 43221675 19, e-mail: drhaticeuce@gmail.com Received: 2.04.2020, accepted: 25.04.2020. 
tor $\alpha$ (TNF- $\alpha$ ) in the T-helper 1 (Th1) pathway, IL-23/12, IL-22 and IL-17. In recent years, Th17 cells have been central to these studies. IL-17A cytokine released from Th17 cells has been identified as the most important effector pathogenic factor in the formation of psoriasis [5]. Apart from psoriasis, IL-17 has been shown to be effective in many diseases such as rheumatoid arthritis, psoriatic arthritis, Crohn's disease, ankylosing spondylitis, multiple sclerosis, uveitis, and asthma [6, 7].

Most of the experimental and clinical studies have shown that IL-17 is a very effective cytokine in the inflammatory process of psoriasis. Therefore, IL-17 inhibitors may be used for the treatment of psoriasis. There are six subunits in the IL-17 family: IL-17A, IL-17B, IL-17C, IL-17D, IL-17E and IL-17F [8]. In an in vitro study, IL-17 has been shown to trigger pro-inflammatory cytokines, metalloproteinases and chemokines in the infection-induced immune response. IL-17A, IL-17C and IL-17F have been observed to have a higher expression in psoriatic skin lesions than in normal skin [9].

Single nucleotide polymorphisms (SNPs) are the displacement of a nucleotide and occur in at least $1 \%$ of the population. SNPS can be found in the coding, intergenic and non-coding regions of genes or promoters [10]. In studies related to gene polymorphisms in psoriasis, a significant relationship has been found in some genes [11-14]. In different studies performed, the polymorphisms of interleukins IL-1 , IL-6, IL-10, IL-16 and IL-17A have also been demonstrated to be associated with the pathogenesis of psoriasis [15-18]. In the study conducted by Kaur et al., decreased frequencies of IL-17A rs104848799 G allele and IL-17F rs763780 C allele have been demonstrated in comparison to controls. In this study, it was asserted that IL-17A rs10484879 and IL-17F rs763780 gene polymorphisms may contribute to the pathogenesis of psoriasis [19]. IL-17A and IL-17F genes are located on chromosome 6p12. rs227593 variation is located in the promotor region of $I L-17 A$ gene and is so close to 2 nuclear factors activated by $T$ cell binding motifs. This variation enhances the expression of IL-17A. IL-17F rs763780 variation leads to the amino acid exchange (His to Arg) at the amino acid position 161 which is located in exon 3. This missense variation inhibits the function of IL-17F [20]. Functional polymorphisms of enzymes that metabolize drugs may play a role in adverse drug reactions. SNPs found in genes encoding some enzymes can increase or decrease drug metabolism. These variations can change the effectiveness of drugs [21, 22]. Pharmacogenetics examines different variations in the DNA sequence related to drug response. However, pharmacogenetic studies in psoriasis have led to controversial results, possibly due to factors such as small study populations and the ethnicity of patients [23].

In recent years, several new biological drugs targeting the IL-23/IL-17A pathway have been approved for the treatment of psoriasis, and some are still under clinical development. These treatments have been proven to bring psoriasis under control as they show unique activity on psoriatic plaques [24]. There are a few studies that investigated the relationship of response to biological agents with polymorphisms of existing cytokines (TNF- $\alpha$, IL-12/23 or IL-17) in psoriasis. In a study performed, IL-17F gene polymorphism was observed to affect the response of narrow-band UVB therapy in psoriatic patients [25].

It can be detected in advance whether the patients will respond to the treatment or not by SNP examinations before initiating the biological medication. Identifying the resistance of patients to biological drugs with these biomarkers will prevent both waste of time and financial losses.

\section{Aim}

In our study, we investigated whether the polymorphisms of IL-17A rs2275913 and IL-17F rs763780 are related to the treatment response in patients using biological medications (secukinumab, adalimumab, ustekinumab, infliximab and etanercept).

\section{Material and methods}

\section{Subject}

Ethics committee approval with number 2019/24 and dated 2019 was obtained for our study. Eighty-three volunteer patients with psoriasis who applied to the dermatology outpatient clinic for psoriasis and who had been on biological medications for at least 6 months were enrolled in the study. Those with additional genetic diseases were not included in the study. Furthermore, 69 healthy volunteers with no systemic disease were included in the study. Concomitant diseases of patients, systemic conventional drugs (methotrexate, cyclosporine, acitretin and UVB-UVA) they used before receiving biological treatment, family history of similar diseases, duration of disease, Psoriasis Area Severity Index (PASI) scores showing the effectiveness of the last biological drug used by the patient and the total biological drug use times were recorded. The response of the patients to the biological drug was classified based on PASI scores as follows: treatment resistant; $\leq$ PASI50, incomplete response to treatment; $\geq$ PASI50, good response to treatment; PASI90 and excellent complete response were classified as PASI100. All participants in the study were 18-80 years of age. Samples of blood taken during the routine control of patients were stored at $-20^{\circ} \mathrm{C}$. After reaching the targeted patient and control number, these were sent to the genetic laboratory in the medical biology department to determine the presence of the polymorphisms of IL-17A rs2275913 and IL-17F rs 763780.

\section{DNA isolation and genotyping}

GF-1 Blood DNA Extraction Kit (Vivantis Technologies, Malaysia) was used for extraction of genomic DNA from 
Table 1. Comparison of genomic frequencies of IL-17A rs2275913 and IL-17F rs763780 variants between psoriatic patients and the control group

\begin{tabular}{ccccccc}
\hline Variable & & \multicolumn{2}{c}{ Patients } & \multicolumn{2}{c}{ Controls } & P-value \\
\cline { 2 - 5 } & & $n$ & $\%$ & $n$ & $\%$ & \\
\hline IL-17A & GG & 34 & 53.1 & 31 & 46.9 & 0.922 \\
\cline { 2 - 5 } & GA & 38 & 55.9 & 30 & 44.1 & \\
\cline { 2 - 5 } & AA & 11 & 57.9 & 8 & 42.1 & \\
\hline IL-17F & TT & 71 & 53.4 & 62 & 46.6 & 0.621 \\
\cline { 2 - 5 } & TC & 10 & 66.7 & 5 & 33.3 & \\
\cline { 2 - 5 } & CC & 2 & 66.7 & 1 & 33.3 & \\
\hline
\end{tabular}

peripheral blood of subjects according to the manufacturer's instructions. TaqMan assays (Thermo Scientific, USA) were used to determine the IL-17A gene rs2275913 and IL-17F gene rs763780 variants. Real Time PCR amplification was performed for SNP genotyping according to the manufacturer's instructions. As brief PCR reaction was $25 \mu \mathrm{l}$ containing $2.25 \mu \mathrm{l}$ at the concentration of 3-20 ng genomic DNA diluted in distilled water, $12.50 \mu \mathrm{l}$ of 2xTaqpath ProAmp Master Mix (2X) (Thermo Scientific, USA) and $1.25 \mu \mathrm{l}$ of 20x TaqMan SNP Assay mix (Thermo Scientific, USA). Manufacturer's instructions were used for the amplification conditions.

\section{Statistical analysis}

SPSS 23.0 package software was used to evaluate the data obtained in the research. In order to compare categorical variables between groups, $\chi^{2}$ and/or Fisher's exact test was used. The $t$-test was utilized in independent groups in order to compare continuous variables between two groups, whereas One-Way Variance Analysis technique was utilized to investigate the difference between more than two groups. Frequency and percentage values were used for categorical variables in order to summarize the results of analysis, whereas average \pm standard deviation, median minimum and maximum values were used in order to summarize the continuous data. For a statistical significance level, $p<0.05$ was used.

\section{Results}

The gender distribution was 34 (41.0\%) females and $49(59.0 \%)$ males in the 83 psoriasis patients enrolled in the study, whereas 29 (42.6\%) females and 39 (57.4\%) males in 69 healthy controls. The mean age of the patients was calculated as $37.59 \pm 14.11$, and of the control group as $35.29 \pm 10.29$. There was no significant difference between the control and patient groups in terms of age and gender. The average age of females in psoriasis patients was found to be 37.28 (age range: 19-75) and 38.2 in the males (19-76). Disease duration was determined as 14.9 (2-35) years in females and 16.38 (2-45 years) in males. There was no statistically significant difference between the gender groups in terms of age and disease duration ( $p=0.823, p=0.486$, respectively). The distribution of both genes for gender was homogeneous in terms of allele categories. It was observed that being a male or female did not affect the observed genotype.

Genotype frequencies of IL-17A rs2275913 and IL-17F rs763780 variants were similar in the control and patient groups. In the population in the eastern Turkey, no significant difference was detected in psoriatic patients in terms of rs2275913 and rs763780 variants as compared to the controls (Table 1).

Upon examination of the IL-17A/rs2275913 variant in terms of disease duration, it was observed that individuals with $A A$ genotype had a shorter disease duration (less than 10 years) compared to the GG genotype, and this value was statistically significant $(p=0.009)$. However, no significant difference was observed for IL-17F/

Table 2. Relationship between IL-17A rs2275913 and IL-17F rs763780 variants and disease duration

\begin{tabular}{|c|c|c|c|c|c|c|c|c|}
\hline \multirow[t]{2}{*}{ Variable } & & & \multicolumn{5}{|c|}{ Disease duration [years] } & \multirow[t]{2}{*}{$P$-value } \\
\hline & & & $<5$ & $5-10$ & $10-20$ & $20-30$ & $>30$ & \\
\hline \multirow[t]{6}{*}{ IL-17A/rs2275913 } & GG & $n$ & 3 & 6 & 18 & 3 & 4 & 0.009 \\
\hline & & $\%$ & 8.8 & 17.6 & 52.9 & 8.8 & 11.8 & \\
\hline & GA & $n$ & 3 & 8 & 13 & 12 & 2 & \\
\hline & & $\%$ & 7.9 & 21.1 & 34.2 & 31.6 & 5.3 & \\
\hline & AA & $n$ & 4 & 5 & 1 & 1 & 0 & \\
\hline & & $\%$ & 36.4 & 45.5 & 9.1 & 9.1 & 0.0 & \\
\hline \multirow[t]{6}{*}{ IL-17F/rs763780 } & TT & $n$ & 9 & 18 & 25 & 13 & 6 & 0.443 \\
\hline & & $\%$ & 12.7 & 25.4 & 35.2 & 18.3 & 8.5 & \\
\hline & $\mathrm{TC}$ & $n$ & 1 & 0 & 6 & 3 & 0 & \\
\hline & & $\%$ & 10.0 & 0.0 & 60.0 & 30.0 & 0.0 & \\
\hline & CC & $n$ & 0 & 1 & 1 & 0 & 0 & \\
\hline & & $\%$ & 0.0 & 50.0 & 50.0 & 0.0 & 0.0 & \\
\hline
\end{tabular}


Table 3. The relationship between IL-17A rs2275913 variant and different parameter results in psoriatic patients

\begin{tabular}{|c|c|c|c|c|c|c|c|c|}
\hline \multirow[t]{2}{*}{ Parameter } & & \multicolumn{2}{|c|}{ GG } & \multicolumn{2}{|c|}{ GA } & \multicolumn{2}{|c|}{ AA } & \multirow[t]{2}{*}{$P$-value } \\
\hline & & $n$ & $\%$ & $n$ & $\%$ & $n$ & $\%$ & \\
\hline \multirow{4}{*}{$\begin{array}{l}\text { Number of } \\
\text { conventional } \\
\text { treatments }\end{array}$} & 1 & 7 & 26.9 & 10 & 38.5 & 9 & 34.6 & \multirow[t]{4}{*}{0.025} \\
\hline & 2 & 12 & 41.4 & 16 & 55.2 & 1 & 3.4 & \\
\hline & 3 & 12 & 54.5 & 9 & 40.9 & 1 & 4.5 & \\
\hline & 4 & 3 & 50.0 & 3 & 50.0 & 0 & 0.0 & \\
\hline \multirow[t]{2}{*}{ Additional disease } & Yes & 11 & 45.8 & 11 & 45.8 & 2 & 8.3 & \multirow[t]{2}{*}{0.711} \\
\hline & No & 23 & 39.0 & 27 & 45.8 & 9 & 15.3 & \\
\hline \multirow[t]{4}{*}{ PASI } & < PASI50 & 1 & 16.7 & 5 & 83.3 & 0 & 0.0 & \multirow[t]{4}{*}{0.003} \\
\hline & > PASI50 & 10 & 50.0 & 9 & 45.0 & 1 & 5.0 & \\
\hline & PASI90 & 15 & 36.6 & 10 & 24.4 & 16 & 39.02 & \\
\hline & PASI100 & 4 & 25.0 & 3 & 18.75 & 9 & 56.25 & \\
\hline \multirow[t]{2}{*}{ Family history } & Yes & 5 & 38.5 & 6 & 46.2 & 2 & 15.4 & \multirow[t]{2}{*}{1.000} \\
\hline & No & 29 & 41.4 & 32 & 45.7 & 9 & 12.9 & \\
\hline \multirow{2}{*}{$\begin{array}{l}\text { Multiple biological } \\
\text { use }\end{array}$} & Yes & 14 & 51.9 & 11 & 40.7 & 2 & 7.4 & \multirow[t]{2}{*}{0.335} \\
\hline & No (naïve) & 20 & 35.7 & 27 & 48.2 & 9 & 16.1 & \\
\hline
\end{tabular}

Table 4. Association of IL-17F rs763780 and IL-17A rs2275913 variants with age, duration of disease, duration of the last biological medication used and total duration of treatment with biological agents

\begin{tabular}{|c|c|c|c|c|c|c|c|c|}
\hline \multirow[t]{2}{*}{ Parameter } & \multicolumn{3}{|c|}{ IL-17F rs763780 } & \multirow[t]{2}{*}{$P$-value } & \multicolumn{3}{|c|}{ IL-17A rs2275913 } & \multirow[t]{2}{*}{$P$-value } \\
\hline & $\begin{array}{c}\mathrm{TT} \\
\text { Mean } \pm \mathrm{SD}\end{array}$ & $\begin{array}{c}\text { TC } \\
\text { Mean } \pm \text { SD }\end{array}$ & $\begin{array}{c}\text { CC } \\
\text { Mean } \pm \text { SD }\end{array}$ & & $\begin{array}{c}\mathrm{GG} \\
\text { Mean } \pm \text { SD }\end{array}$ & $\begin{array}{c}\mathrm{GA} \\
\text { Mean } \pm \mathrm{SD}\end{array}$ & $\begin{array}{c}\text { AA } \\
\text { Mean } \pm \text { SD }\end{array}$ & \\
\hline Age & $37 \pm 14$ & $37 \pm 13$ & $24 \pm 7$ & 0.254 & $38 \pm 14$ & $39 \pm 15$ & $31 \pm 11$ & 0.114 \\
\hline Disease duration & $15.63 \pm 9.75$ & $17.50 \pm 7.66$ & $12.50 \pm 3.53$ & 0.748 & $16.76 \pm 10.22$ & $16.84 \pm 8.67$ & $9.09 \pm 6.82$ & 0.020 \\
\hline $\begin{array}{l}\text { The last biologic } \\
\text { treatment duration }\end{array}$ & $2.43 \pm 1.84$ & $1.60 \pm 0.84$ & $1.00 \pm 0.00$ & 0.216 & $1.79 \pm 0.95$ & $2.82 \pm 2.17$ & $2.09 \pm 1.81$ & 0.138 \\
\hline $\begin{array}{l}\text { Total biologic } \\
\text { treatment duration }\end{array}$ & $3.28 \pm 2.36$ & $4.10 \pm 3.51$ & $3.50 \pm 3.53$ & 0.634 & $3.41 \pm 2.54$ & $3.47 \pm 2.24$ & $3.00 \pm 3.46$ & 0.337 \\
\hline
\end{tabular}

rs763780 gene in terms of T-C change (Table 2). Upon examination in terms of IL-17A/rs2275913 variant in those who use a single conventional medication, it was observed that most of the patients had the AA genotype $(p=0.025)$. Moreover, it was found that those using four conventional drugs did not have the AA genotype. In patients with PASI90 and PASI100, the IL-17A/rs2275913 variant was significantly higher in the AA genotype $(p=0.003)$ (Table 3). That is, in patients with good response to treatment, the AA genotype was significantly higher in the IL-17A/rs2275913 variant. However, no significant relationship was identified between the IL-17F/rs763780 gene, T-C change and the age of the patients, duration of the biological medication used, presence of concomitant diseases, and multiple biological drug use (Tables 4 and 5).

Upon examination of the last biological drug used by the patients, it was observed that secukinumab (38.6\%) was the most used biological drug in 32 patients. Other biologicals included adalimumab 34.9\% (29 patients), ustekinumab 13.3\% (11 patients), infliximab 8.4\% (7 patients), and etanercept $4.8 \%$ (4 patients). Upon examination of the duration of use of the most recently used biological drugs, it was observed that the longest continuity was present in those who use infliximab (3.85 \pm 2.47 years). The examination of the total duration of biological drug use revealed that the longest duration was present in patients using infliximab (4.42 \pm 2.14 years). However, no significant difference was observed with other biological drugs. Total duration of biological drug use in males was significantly higher than in females $(p=0.041)$. No significant difference was identified in the genetic examinations based on all biological drugs used in terms of IL-17A/rs2275913 and IL-17F/rs763780 variants (Table 6).

The assessment of the relationship between PASI scores and biological drugs revealed secukinumab as the 
Table 5. Relationship between IL-17F rs763780 variant and different parameter results in psoriatic patients

\begin{tabular}{|c|c|c|c|c|c|c|c|c|}
\hline \multirow[t]{2}{*}{ Parameter } & & \multicolumn{2}{|c|}{ TT } & \multicolumn{2}{|c|}{ TC } & \multicolumn{2}{|c|}{ CC } & \multirow[t]{2}{*}{$P$-value } \\
\hline & & $n$ & $\%$ & $n$ & $\%$ & $n$ & $\%$ & \\
\hline \multirow{4}{*}{$\begin{array}{l}\text { Number of } \\
\text { conventional } \\
\text { treatments }\end{array}$} & 1.00 & 22 & 84.6 & 3 & 11.5 & 1 & 3.8 & \multirow[t]{4}{*}{0.901} \\
\hline & 2.00 & 25 & 86.2 & 4 & 13.8 & 0 & 0.0 & \\
\hline & 3.00 & 19 & 86.4 & 2 & 9.1 & 1 & 4.5 & \\
\hline & 4.00 & 5 & 83.3 & 1 & 16.7 & 0 & 0.0 & \\
\hline \multirow{2}{*}{$\begin{array}{l}\text { Additional } \\
\text { disease }\end{array}$} & Yes & 22 & 91.7 & 2 & 8.3 & 0 & 0.0 & \multirow[t]{2}{*}{0.296} \\
\hline & No & 49 & 83.1 & 8 & 13.6 & 2 & 3.4 & \\
\hline \multirow[t]{4}{*}{ PASI } & < PASI50 & 6 & 100.0 & 0 & 0.0 & 0 & 0.0 & \multirow[t]{4}{*}{0.990} \\
\hline & $>$ PASI50 & 17 & 85.0 & 3 & 15.0 & 0 & 0.0 & \\
\hline & PASI90 & 34 & 82.9 & 5 & 12.2 & 2 & 4.9 & \\
\hline & PASI100 & 14 & 87.5 & 2 & 12.5 & 0 & 0.0 & \\
\hline \multirow[t]{2}{*}{ Family history } & Yes & 11 & 84.6 & 2 & 15.4 & 0 & 0.0 & \multirow[t]{2}{*}{0.758} \\
\hline & No & 60 & 85.7 & 8 & 11.4 & 2 & 2.9 & \\
\hline \multirow{2}{*}{$\begin{array}{l}\text { Multiple biological } \\
\text { agent use }\end{array}$} & Yes & 21 & 77.8 & 5 & 18.5 & 1 & 3.7 & \multirow[t]{2}{*}{0.296} \\
\hline & No (naïve) & 50 & 89.3 & 5 & 8.9 & 1 & 1.8 & \\
\hline
\end{tabular}

Table 6. Association of IL-17A rs2275913 and IL-17F rs763780 variants with biological agents

\begin{tabular}{|c|c|c|c|c|c|c|c|c|}
\hline \multirow[t]{2}{*}{ Variable } & & & \multicolumn{5}{|c|}{ Biological agents } & \multirow[t]{2}{*}{$P$-value } \\
\hline & & & Adalimumab & Secukinumab & Infliximab & Ustekinumab & Etanercept & \\
\hline \multirow[t]{6}{*}{ IL-17A/rs2275913 } & \multirow[t]{2}{*}{ GG } & $n$ & 41.2 & 2.9 & 20.6 & 8.8 & 41.2 & \multirow[t]{6}{*}{0.297} \\
\hline & & $\%$ & 41.2 & 2.9 & 20.6 & 8.8 & 41.2 & \\
\hline & \multirow[t]{2}{*}{ GA } & $n$ & 17 & 12 & 5 & 3 & 1 & \\
\hline & & $\%$ & 44.7 & 31.6 & 13.2 & 7.9 & 2.6 & \\
\hline & \multirow[t]{2}{*}{ AA } & $n$ & 41.2 & 2.9 & 20.6 & 8.8 & 41.2 & \\
\hline & & $\%$ & 41.2 & 2.9 & 20.6 & 8.8 & 41.2 & \\
\hline \multirow[t]{6}{*}{ IL17F/rs763780 } & TT & $n$ & 28 & 26 & 7 & 8 & 2 & \multirow[t]{6}{*}{0.071} \\
\hline & & $\%$ & 39.4 & 36.6 & 9.9 & 11.3 & 2.8 & \\
\hline & $\mathrm{TC}$ & $n$ & 1 & 5 & 0 & 2 & 2 & \\
\hline & & $\%$ & 10.0 & 50.0 & 0.0 & 20.0 & 20.00 & \\
\hline & $\mathrm{CC}$ & $n$ & 0 & 1 & 0 & 1 & 0 & \\
\hline & & $\%$ & 0.0 & 50.0 & 0.0 & 50.0 & 0.0 & \\
\hline
\end{tabular}

Table 7. The relationship between the number of the patients who use biological medication and Psoriasis Area Severity Index (PASI) score

\begin{tabular}{|c|c|c|c|c|c|c|c|c|c|c|}
\hline \multirow[t]{2}{*}{ PASI } & \multicolumn{2}{|c|}{ Adalimumab } & \multicolumn{2}{|c|}{ Secukinumab } & \multicolumn{2}{|c|}{ Infliximab } & \multicolumn{2}{|c|}{ Ustekinumab } & \multicolumn{2}{|c|}{ Etanercept } \\
\hline & $n$ & $\%$ & $n$ & $\%$ & $n$ & $\%$ & $n$ & $\%$ & $n$ & $\%$ \\
\hline$<$ PASI50 & 2 & 33.3 & 0 & 0.0 & 3 & 50.0 & 1 & 16.7 & 0 & 0.0 \\
\hline > PASI50 & 10 & 50.0 & 1 & 5.0 & 3 & 15.0 & 3 & 15.0 & 3 & 15.0 \\
\hline PASI90 & 17 & 41.5 & 15 & 36.6 & 1 & 2.4 & 7 & 17.1 & 1 & 2.4 \\
\hline PASI100 & 0 & 0.0 & 16 & 100.0 & 0 & 0.0 & 0 & 0.0 & 0 & 0.0 \\
\hline Total & 29 & 34.9 & 32 & 38.6 & 7 & 8.4 & 11 & 13.3 & 4 & 4.8 \\
\hline
\end{tabular}


most successful drug. PASI100 score was detected only in patients using secukinumab. There was no significant difference in PASI scores in male and female patients. We found that treatment success was higher in naive patients, that is, in those who used a biological drug for the first time. Improvement values in PASI were found to be significantly higher in naïve patients (Table 7).

The mean age of those who used all of the conventional drugs, namely methotrexate, cyclosporine, acitretin and all of the UVB-UVA treatments was found to be 64.67 and significantly higher $(p=0.001)$. In addition, it was observed that the use of more than one biological drug increased significantly as the number of conventional drugs increased $(p=0.006)$. Again, a positive correlation was identified between the number of conventional drugs and the duration of biological drug use. That is, as the number of conventional treatments increased, the duration of biological drug use increased $(r=0.547$, $p=0.001$ ). Furthermore, PASI scores were found to decrease as the number of conventional drugs increased (Table 8). Therefore, the group considered as a resistant patient group had a high conventional drug number and multiple biological drug use, and the duration of biological drug use was longer.

\section{Discussion}

In our study, we examined the relationship between the polymorphism in genes encoding IL-17A and IL-17F, which are the most important cytokines in the pathogenesis of psoriasis, and the treatment-response in patients using biological drugs. At the end of the study, we determined that the IL-17A/rs2275913 variant was significantly associated with the treatment outcomes. However, we observed no significant difference in terms of IL-17A/ rs2275913 and IL-17F/rs763780 polymorphisms between psoriasis patients and healthy controls in eastern Turkey. Indeed, different results have been reported in the literature regarding these and similar gene variants. For example, in a study conducted in the Korean society, it was noted that the T/C genotype of the IL-17F/rs763780 variant was strongly associated with psoriasis [26]. However, in a study conducted in Japan, no significant association was reported between the IL-17F/rs763780 variant and the psoriatic patients [27]. In two different studies, it has been suggested that several SNPS on TNF may be biomarkers of treatment with biologicals [28, 29]. In another study, it was suggested that there was a significant relationship between $I L-17 F$ and response times to treatment with biological drugs such as ustekinumab, infliximab and adalimumab $[27,30]$. However, a study that examined the peroxisome proliferator-activated receptor gene polymorphism in psoriatic patients demonstrated that there was no relationship between the narrow-band UVB response and polymorphism [31].
Table 8. The relationship of the number of conventional (MTX, CYSP, ACT, UVB-A) treatments with PASI scores achieved after biological drug use

\begin{tabular}{lccccc}
\hline PASI & \multicolumn{5}{c}{$\begin{array}{r}\text { Number of conventional treatments } \\
\text { used before biological drug }\end{array}$} \\
\cline { 2 - 6 } & & $\mathbf{1}$ & $\mathbf{2}$ & $\mathbf{3}$ & $\mathbf{4}$ \\
\hline PASI < 50 & $n$ & 0 & 4 & 1 & 1 \\
\cline { 2 - 6 } & $\%$ & 0.0 & 66.7 & 16.7 & 16.7 \\
\hline PASI > 50 & $n$ & 4 & 8 & 7 & 1 \\
\cline { 2 - 6 } & $\%$ & 20.0 & 40.0 & 35.0 & 5.0 \\
\hline PASI90 & $n$ & 16 & 12 & 10 & 3 \\
\hline PASI100 & $\%$ & 39.0 & 29.3 & 24.4 & 7.3 \\
\cline { 2 - 6 } & $n$ & 6 & 5 & 4 & 1 \\
\hline mTX methotrexate & CYSP & 37.5 & 31.3 & 25.0 & 6.3 \\
\hline
\end{tabular}

$A-B$.

In a study conducted in Spain, it was noted that IL17RArs/879557, IL-17A/rs7747904 and IL-17F/ rs763780 variants were not associated with psoriasis, but IL-17F/ rs2397084 variant was associated with early onset in patients with psoriasis. However, it was shown in the same study that the IL-17A/rs774909 variant was not associated with psoriatic arthritis [14]. In another study examining the gene polymorphism of patients with psoriatic arthritis, IL-17A/rs7747909 and IL-17RA/rs9606615, rs2241046, rs2241049 variants were found to be very weakly associated with psoriatic arthritis [32]. In most of the studies, it was determined that there was no relationship between genes present and psoriasis. Therefore, our results were found to be compatible with the literature.

In a study conducted in 2018, the relationship of response to anti-TNF (adalimumab, infliximab and etanercept) agents with genes was examined and it was reported that there was a relationship between IL-17RA/ rs4819554 genotype and the response to treatment at week 12 [33]. In the study conducted by Prieto-Perez et al., it was found that there was a significant relationship between response to adalimumab and ustekinumab and IL-17F polymorphism [30].

In our study, the IL-17A/rs2275913 variant was significantly higher in the AA genotype in patients with PASI90 and PASI100. Moreover, we found that patients with short disease duration and who use a single conventional medication had an AA genotype. In the light of these data, it has been shown that patients with the AA genotype of the IL-17A/rs2275913 variant respond better to treatment than those with GG and GA genotypes.

In a study conducted by Seleit et al., the peroxisome proliferator-activated receptor gene polymorphism was examined in psoriatic patients who received narrowband UVB therapy, but no association was found with treatment results [31]. 
IL-17A fibroblasts stimulate epithelial and endothelial cells, leading to the production of inflammatory mediators. In addition, by establishing a link between the natural and acquired immune system, it mobilizes and activates the neutrophils [5]. The close relationship between IL-17A and TNF- $\alpha$ also increases the response of keratinocytes to inflammatory cytokines. Therefore, proinflammatory effects on keratinocytes and neutrophils in psoriasis have been shown to be dependent on both IL-17A and IL-17F [14, 33].

In a study by Johnston et al., it was observed that the expression of IL-17RC decreased in keratinocytes with TNF blockade, therefore, the response of tissues to IL-17A decreased. The persistence of psoriasis lesions increases with strong synergy between TNF and IL-17. This may explain the relationship between anti-TNF response and IL17RA gene variants [34]. In our study, the results of both anti-TNF agents and biological drugs directly blocking IL-17A were compared. The drug that reached PASI100 score at the highest rate was secukinumab, which blocks IL-17A. Furthermore, the significant relationship between good response to treatment and the $/ L-17 A / r s 2275913$ variant supports our results.

Nowadays, PASI90 and PASI100 scores are targeted in treatment with the use of biological drugs in psoriasis $[35,36]$. In our study, we achieved these effective results, especially PASI100 scores, with secukinumab, which is the drug targeting IL-17A. Adalimumab, which is the last anti-TNF agent, had also a high success rate in treatment. Considering the relationship between TNF and IL-17 mentioned above, our results were considered to be in line with the literature. Therefore, the results that we achieved showed that the IL-17 pathway plays a very important role in the pathogenesis of psoriasis.

Biological drugs (adalimumab, secukinumab, etc.) are indicated for patients with moderate to severe psoriasis who do not respond to conventional systemic treatments. These drugs are specific targeted treatments and are molecules that make very little immunosuppression [37]. In recent years, the IL-17 cytokine, which is located on the IL-17 pathway, has been mostly targeted. It is stated in many sources that the highest and fastest treatment results are with drugs acting on this pathway [38-40]. Secukinumab and ixekizumab are the newest biological agents recently approved for the treatment of plaque psoriasis. These agents selectively bind and neutralize interleukin-17A, which is the primary effector of Th17 cells [41]. In our study, secukinumab (IL-17 inhibitor) was evaluated as the biological drug with the highest rate of treatment success in our patients with psoriasis. In our study, there was no significant genotype difference in terms of IL-17A/rs2275913 and IL-17F/rs763780 variants in the genetic examinations performed based on all biological drugs. Upon comparison of the treatment outcomes, no significant relation was found in terms of gene polymorphism despite the high treatment efficacy obtained in secukinumab. Therefore, it is not clear whether the success of the treatment is directly related to the drug.

\section{Conclusions}

As a result, we did not identify a significant difference in IL-17A and IL-17F gene polymorphisms between healthy controls and patients with psoriasis in eastern Turkey. However, we found that the IL-17A/rs2275913 variant being in the AA genotype showed a significant difference in the response of patients to treatment. Since there are no similar studies in our country, we could not compare the results with the data for the Turkish society. In addition, the limitations of our study included underuse of some biological drugs. There is a need for multicentre studies with more patients enrolled where larger numbers of genes are examined.

\section{Acknowledgments}

Van YYU - BAP provided financial support to this clinical trial.

\section{Conflict of interest}

The authors declare no conflict of interest.

\section{References}

1. Dand N, Mahil SK, Capon F, et al. Psoriasis and genetics. Acta Derm Venereol 2020; 30: 55-64.

2. Oskay T, Kundakci N. Genetic findings in psoriasıs. T Klin J Dermatol 2000; 10: 139-45.

3. Capon F. The genetic basis of psoriasis. Int J Mol Sci 2017; 18: pii: E2526.

4. Stylianaki EA, Karpouzis A, Tripsianis G, Veletza S. Assessment of gap junction protein beta-2 rs3751385 gene polymorphism in psoriasis vulgaris. J Clin Med Res 2019; 11: 642-50.

5. Pușcaș AD, Cătană A, Pușcaș C, et al. Psoriasis: association of interleukin-17 gene polymorphisms with severity and response to treatment. Exp Ther Med 2019; 18: 875-80.

6. Gaffen SL, Kramer JM, Yu JJ, Shen F. The IL-17 cytokine family. Vitam Horm 2006; 74: 255-82.

7. Miossec $\mathrm{P}$, Kolls JK. Targeting IL-17 and TH17 cells in chronic inflammation. Nat Rev Drug Discov 2012; 11: 763-76.

8. Martin DA, Towne JE, Kricorian G, et al. The emerging role of $\mathrm{IL}-17$ in the pathogenesis of psoriasis: preclinical and clinical findings. J Invest Dermatol 2013; 133: 17-26.

9. Johansen C, Usher PA, Kjellerup RB, et al. Characterization of the interleukin-17 isoforms and receptors in lesional psoriatic skin. Br J Dermatol 2009; 160: 319-24.

10. Roden DM, Wilke RA, Kroemer HK, Stein CM. Pharmacogenomics: the genetics of variable drug responses. Circulation 2011; 123: 1661-70.

11. Keni FM, Celik SK, Solak N, et al. Relationship between TLR2 and TLR4 gene polymorphisms with psoriasis. Turk J Dermatol 2018; 12: 28-32.

12. Ermis E, Celik SK, Solak N, et al. The role of GNLY gene polymorphisms in psoriasis pathogenesis. An Bras Dermatol 2019; 94: 198-203. 
13. Elsohafy MA, Elghzaly AA, Abdelsalam HM, Gaballah MA. Assessment of the possible role of FOXP3 gene (rs3761548) polymorphism in psoriasis vulgaris susceptibility and pathogenesis: Egyptian study. Indian Dermatol Online J 2019; 10: 401-5.

14. Batalla A, Coto E, González-Lara L, et al. Association between single nucleotide polymorphisms IL17RA rs4819554 and IL17E rs79877597 and psoriasis in a Spanish cohort. J Dermatol Sci 2015; 80: 111-5.

15. Prieto-Pérez R, Solano-López G, Cabaleiro T, et al. Polymorphisms associated with age at onset in patients with moderate-to-severe plaque psoriasis. J Immunol Res 2015; 2015: 101879

16. Patel DD, Lee DM, Kolbinger F, Antoni C. Effect of IL-17A blockade with secukinumab in autoimmune diseases. Ann Rheum Dis 2013; 72: 116-23.

17. Girolomoni G, Mrowietz U, Paul C. Psoriasis: rationale for targeting interleukin-17. Br J Dermatol 2012; 167: 717-24.

18. Isac L, Jiquan S. Interleukin 10 promotor gene polymorphism in the pathogenesis of psoriasis. Acta Dermatovenerol Alp Pannonica Adriat 2019; 28: 119-23.

19. Kaur R, Rawat AK, Kumar S, et al. Association of genetic polymorphism of interleukin-17A and interleukin-17F with susceptibility of psoriasis. Indian J Med Res 2018; 148: 422-6.

20. Dai ZM, Zhang TS, Lin S, et al. Role of IL-17A rs2275913 and IL-17F rs763780 polymorphisms in risk of cancer development: an updated meta-analysis. Sci Rep 2016; 6: 20439.

21. Agúndez JA, Abad-Santos F, Aldea A, et al. Toward a clinical practice guide in pharmacogenomics testing for functional polymorphisms of drug-metabolizing enzymes. Gene/drug pairs and barriers perceived in Spain. Front Genet 2012; 3: 273.

22. Sutherland A, Power RJ, Rahman P, O'Rielly DD. Pharmacogenetics and pharmacogenomics in psoriasis treatment: current challenges and future prospects. Expert Opin Drug Metab Toxicol 2016; 12: 923-35.

23. Ovejero-Benito MC, Muńoz-Aceituno E, Reolid A, et al. Pharmacogenetics and pharmacogenomics in moderate-to-severe psoriasis. Am J Clin Dermatol 2018; 19: 209-22.

24. Brembilla NC, Senra L, Boehncke WH. The IL-17 family of cytokines in psoriasis: IL-17A and beyond. Front Immunol 2018; 9: 1682

25. Białecka M, Ostasz R, Kurzawski M, et al. IL17A and IL17F gene polymorphism association with psoriasis risk and response to treatment in a Polish population. Dermatology 2016; 232: 592-6.

26. Kim SY, Hur MS, Choi BG, et al. A preliminary study of new single polymorphisms in the Thelper type 17 pathway for psoriasis in the Korean population. Clin Exp Immunol 2017; 187: 251-8.

27. Shibata S, Saeki H, Tsunemi Y, et al. IL-17F single nucleotide polymorphism is not associated with psoriasis vulgaris or atopic dermatitis in the Japanese population. J Dermatol Sci 2009; 53: 163-5.

28. Linares-Pineda TM, Canadas-Garre M, Sanchez-Pozo A, Calleja-Hernandez MA. Gene polymorphisms as predictors of response to biological therapies in psoriasis patients. Pharmacol Res 2016; 113: 71-80.

29. Prieto-Pérez R, Solano-López G, Cabaleiro T, et al. New polymorphisms associated with response to anti-TNF drugs in patients with moderate-to-severe plaque psoriasis. Pharmacogenom J 2018; 18: 70-5.

30. Prieto-Pérez R, Solano-López G, Cabaleiro T, et al. The polymorphism rs763780 in the IL-17F gene is associated with response to biological drugs in patients with psoriasis. Pharmacogenomics 2015; 16: 1723-31.
31. Seleit I, Bakry OA, Abd El Gayed E, Ghanem M. Peroxisome proliferator-activated receptor-gamma gene polymorphism in psoriasis and its relation to obesity, metabolic syndrome, and narrowband ultraviolet $B$ response: a case-control study in Egyptian patients. Indian J Dermatol 2019; 64: 192-200.

32. Catanoso MG, Boiardi L, Macchioni P, et al. IL-23A, IL-23R, IL-17A and IL-17R polymorphisms in different psoriatic arthritis clinical manifestations in the northern Italian population. Rheumatol Int 2013; 33: 1165-76.

33. Batalla A, Coto E, Gómez J, et al. IL17RA gene variants and anti-TNF response among psoriasis patients. Pharmacogenom J 2018; 18: 76-80.

34. Johnston A, Guzman AM, Swindell WR, et al. Early tissue responses in psoriasis to the antitumour necrosis factor-alpha biologic etanercept suggest reduced interleukin-17 receptor expression and signalling. Br J Dermatol 2014; 171: 97-107.

35. Galluzzo M, Talamonti M, De Simone C, et al. Secukinumab in moderate-to-severe plaque psoriasis: a multi-center, retrospective, real-life study up to 52 weeks observation. Expert Opin Biol Ther 2018; 18: 727-35.

36. Pinter A, Gerdes S, Papavassilis C, Reinhardt M. Characterization of responder groups to secukinumab treatment in moderate to severe plaque psoriasis. J Dermatolog Treat 2019; 16: 1-7.

37. Reid C, Griffiths CEM. Psoriasis and treatment: past, present and future aspects. Acta Derm Venereol 2020; 100: 69-79.

38. Blauvelt A, Chiricozzi A. The immunologic role of IL-17 in psoriasis and psoriatic arthritis pathogenesis. Clin Rev Allergy Immunol 2018; 55: 379-90.

39. Tsai TF. Secukinumab in patients with psoriasis who have responded inadequately to tumour necrosis factor inhibitor treatment. Br J Dermatol 2020 doi: 10.1111/bjd.18869.

40. Rompoti N, Katsimbri P, Kokkalis G, et al. Real world data from the use of secukinumab in the treatment of moderate-to-severe psoriasis, including scalp and palmoplantar psoriasis: a 104-week clinical study. Dermatol Ther 2019; 32: e13006.

41. Liau MM, Oon HH. Therapeutic drug monitoring of biologics in psoriasis. Biologics 2019; 13: 127-32. 